
Not for reproduction, distribution or commercial use.



This article appeared in a journal published by Elsevier. The attached copy is furnished to the author for internal non-commercial research and education use, including for instruction at the authors institution and sharing with colleagues.

Other uses, including reproduction and distribution, or selling or licensing copies, or posting to personal, institutional or third party websites are prohibited.

In most cases authors are permitted to post their version of the article (e.g. in Word or Tex form) to their personal website or institutional repository. Authors requiring further information regarding Elsevier's archiving and manuscript policies are encouraged to visit:

http://www.elsevier.com/copyright 


\title{
Optical modeling as optimization tool for single and double junction polymer solar cells
}

\author{
W. Eerenstein ${ }^{a, *}$, L.H. Slooff ${ }^{a}$, S.C. Veenstra ${ }^{a, b}$, J.M. Kroon ${ }^{\text {a,b }}$ \\ a Energy research Centre of the Netherlands (ECN), PO Box 1, 1755 ZG Petten, The Netherlands \\ ${ }^{\mathrm{b}}$ Dutch Polymer Institute, Eindhoven, 5600 AX, The Netherlands
}

Available online 17 December 2007

\begin{abstract}
We have used optical modeling to calculate whether optical absorption and corresponding current densities in solar cells consisting of PF10TBT:PCBM (1:4) can be enhanced, either in single junctions by applying optical spacers or by going to a tandem structure. The current densities are calculated from the optical absorption using experimentally determined IQE values. When an optical spacer is used, the thickness of the transparent electron transport layer (ETL) and hole transport layer (HTL) is very important. The absorption, and thus current density, in a single junction solar cell could be enhanced by $10 \%$ by reducing the HTL (PEDOT) thickness and by inserting a thin ETL ( $30 \mathrm{~nm}$ ZnO). The current density in a tandem consisting of two PF10TBT:PCBM blend layers is strongly dependent on the thickness of these blend layers. An increase of $20 \%$ is possible for a layer combination of $150 \mathrm{~nm}$ and $250 \mathrm{~nm}$, combined with appropriate ETL and HTL layer thicknesses, and assuming no further losses.
\end{abstract}

(C) 2007 Elsevier B.V. All rights reserved.

Keywords: Optical modeling; Polymer solar cells; Tandem structures; Polyfluorenes

\section{Introduction}

Organic and polymer based solar cells have been studied intensively [1,2], as their production costs are expected to be significantly lower than for conventional silicon based solar cells. However, two main hurdles that have to be overcome are the relatively low efficiency and stability of polymer based solar cells. An efficiency of a polymer solar cell consisting of a blend of a light absorbing electron donating polymer and [C60]PCBM electron acceptor well above $2 \%$ was first reported in 2001 [3], and the highest independently verified value reported to date is $4.8 \%$ [4], although recently values of $5.5 \%$ have been reported [5].

The most intensively studied combination of materials is the polymer material P3HT mixed with [C60]PCBM, for which device efficiencies between $4-5 \%$ have been reported $[6,7]$. These P3HT:PCBM solar cells have a $V_{\mathrm{oc}}$ value around $0.6 \mathrm{~V}$, and a current density between $10-12 \mathrm{~mA} / \mathrm{cm}^{2}$ [2,4]. The polyfluorene polymer PF10TBT has the same optical bandgap as

\footnotetext{
* Corresponding author.

E-mail addresses: eerenstein@ecn.nl (W. Eerenstein),j.kroon@ecn.nl (J.M. Kroon).
}

P3HT (around $2 \mathrm{eV}$ ) and the optical absorption of P3HT and PF10TBT are thus expected to be similar. However, devices based on PF10TBT and PCBM [8-10] have a larger $V_{\text {oc }}$ of $1 \mathrm{~V}$ due to a different position of the energy levels. Unfortunately, the measured current density in PF10TBT is lower, about $8 \mathrm{~mA} / \mathrm{cm}^{2}$ [8]. It is therefore expected that an increase in current density would lead to efficiencies above those of P3HT based devices. The maximum current density occurs for films with a thickness around $200 \mathrm{~nm}$, although the absorption is then not yet saturated [8], indicating that the trade off between light absorption and collection efficiency limits the current density, and thus the performance of PF10TBT:PCBM solar cells. Here, we will consider two options to increase the light absorption. First, we investigate whether it is possible to increase light absorption in a blend layer by using optical spacer layers. Secondly, we examine whether a tandem structure could improve light absorption and current generation in the overall device.

In so-called tandem solar cells two individual cells are stacked on top of each other (see Fig. 1). Ideally, a tandem cell consists of two individual cells with different band gap materials such that each subcell can absorb light from a different part of the optical spectrum. However, tandem structures can also consist of 


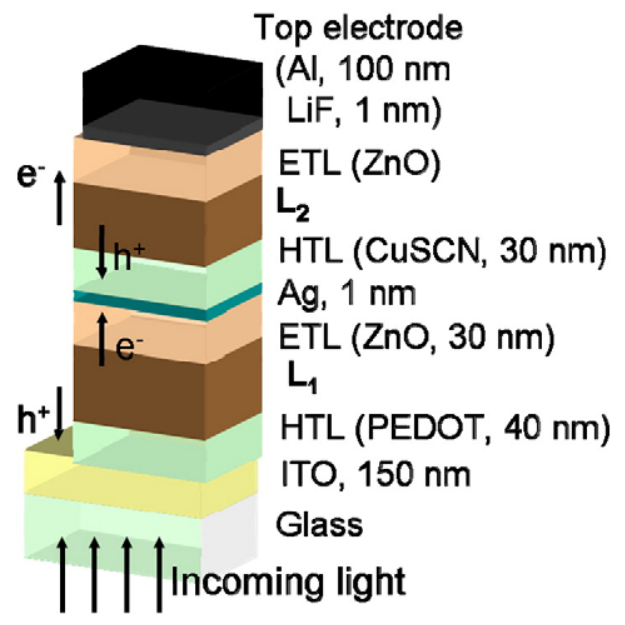

Fig. 1. Structure of the tandem cell in a series configuration. On the glass substrate, a $150 \mathrm{~nm}$ ITO and a hole transport layer (e.g. PEDOT:PSS) serve as hole collecting bottom contact. The polymer blend layers $L_{1}$ and $L_{2}$ consist of PF10TBT:PCBM=1:4. The two blend layers are separated by $\mathrm{ZnO}$ (electron transport) and $\mathrm{CuSCN}$ (hole transport), where a very thin $\mathrm{Ag}$ layer serves as a recombination layer. The top electron collecting contact consists of $1 \mathrm{~nm} \mathrm{LiF}$ and $100 \mathrm{~nm} \mathrm{Al}$.

two cells of the same material [11-14]. Tandem cells are often connected in a two-terminal series configuration, where the total $V_{\mathrm{oc}}$ of the tandem is the sum of the $V_{\mathrm{oc}}$ of the individual cells, and the current is determined by the cell with the lowest current [15]. The reason for choosing a two-terminal series rather than a parallel configuration (three terminal) is that in the parallel configuration an extra electrode needs to be put between the first and second subcell. As these are usually metals, they will absorb light, thereby reducing the absorption and thus the current in the second subcell. In a two-terminal series configuration, such electrodes are not necessary.

In polymer tandem cells, the second cell can only be processed directly on top of the first cell when the solvents of both layers are incompatible. As this is unlikely in practice, the two cells need to be physically separated. Ideally, this separation layer must be optically transparent. This layer can also have additional functions, as it is used as either an electron or hole conducting layer (ETL and HTL respectively) to form selective contacts to the sub-cells. By combining electron and hole transporting layers, recombination layers are created (possibly with an additional thin metal layer) as shown in Fig. 1. Finally, these layers can also operate as optical spacer layers that locally change the electric field in the blend layer such that the absorption might be enhanced.

Tandem cells have been shown to work well for inorganic solar cells, e.g. for a combination of amorphous Si and GaAs solar cells [16]. Working polymer based tandems and double junctions have been fabricated [11-15], but their performance is often lower than for single cell solar cells due to a low limiting current in one of the subcells. Only recently has a tandem in which both cells produce a large current density been reported [17]. In the current paper, we use optical modeling to calculate whether the absorption in single cell devices and in tandem multi-junctions can further be increased by changing the thickness of HTL and ETL layers. It is also demonstrated how the current density in polymer tandem cells, consisting of two subcells of PF10TBT:PCBM blend layers, changes with the thickness of both blend layers. Optical modeling is shown to be a useful tool to aid the design of appropriate configurations for solar cells.

\section{Modeling of optical absorption and calculated current density}

The reflection and absorption of light with a particular wavelength depends on the optical constants of the materials. These have been determined by ellipsometry. The optical absorption in the layers has been calculated using SCOUT [18], using a transfer matrix formalism [19-21]. The interference pattern for each wavelength results from multiple reflections at the various interfaces, and depends on the thickness of the layers. The absorption distribution for each wavelength over the film thickness has been calculated in the wavelength range 300$800 \mathrm{~nm}$. Multiplying with the light spectrum (photon flux, $\mathrm{m}^{-2} \mathrm{~s}^{-1} \mathrm{~nm}^{-1}$ ) of either the AM1.5 spectrum or the actual lamp spectrum, and integration over the film thickness results in the total number of photons absorbed for each wavelength. Lastly, a summation over all wavelength results in the total number of absorbed photons $\left(\mathrm{m}^{-2} \mathrm{~s}^{-1}\right)$. The maximum current density can be calculated assuming that each absorbed photons results in a collected electron (i.e. the internal quantum efficiency, IQE, equals one). In most polymer solar cells, the IQE is lower than one due to several effects, particularly charge recombination. Therefore, the true current density can not be described by optical modeling alone and an electrical model $[22,23]$ is necessary. This is beyond the scope of the present paper. Instead, we will use an empirical determination of the IQE, which has been determined from the ratio of the measured current density and the calculated maximum current density. These values of the IQE have been determined for single junction solar cells. As the charge collection efficiency also depends on how far from the electrode the charges have been generated (in other words, at which depth the light has been absorbed), it depends on film thickness and on the interference pattern of the light profile. This is not exactly equal for tandem structures and single junction cells. Therefore our empirical approach is not sufficient to calculate the exact current density in tandem structures, but is a useful aid to study thickness effects and optimize device design.

\section{Results and discussion}

\subsection{Single junction}

Fig. 2a shows the calculated absorption density in PF10TBT: PCBM (1:4) solar cells as a function of film thickness for illumination with a halogen lamp. If every absorbed photon generates an electron, we obtain the calculated current density shown in Fig. 2b. However, Fig. 2b also shows the measured current density (measured under halogen lamp). Although the absorption increases with film thickness, up to at least $500 \mathrm{~nm}$, the current reaches its maximum value for films with a thickness around $200 \mathrm{~nm}$. This is due to the low product of mobility and 


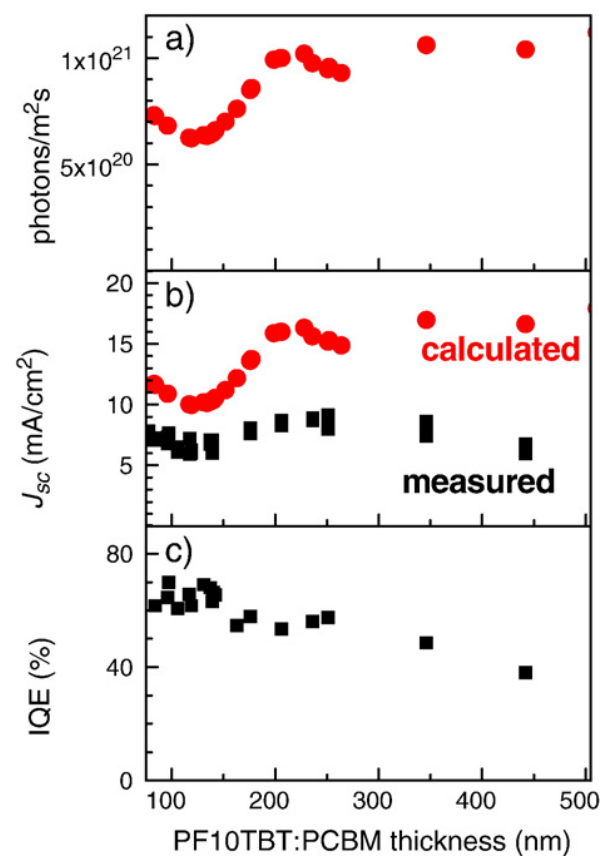

Fig. 2. a) Calculated optical absorption (nr. of absorbed photons per $\mathrm{m}^{2}$ per second) in a PF10TBT:PCBM blend layer as a function of blend thickness. b) Corresponding calculated current density assuming $\mathrm{IQE}=1$ (red squares) and measured current density (black circles). Both the calculated and measured current densities are basedon the halogen lamp spectrum c) the IQE is the ratio of the measured and calculated current densities.

lifetime of the charge carriers. This is reflected in the value of the internal quantum efficiency (see Fig. 2c) which has the largest value of $75 \%$ for films below $150 \mathrm{~nm}$, but reduces to $60 \%$ for thicknesses of $150-275 \mathrm{~nm}$ and to $50 \%$ for film thicknesses of 275-325 nm [8]. These values of the IQE will be used for the calculations of the current densities.

We calculated whether the optical absorption, and corresponding current density, in PF10TBT:PCBM single junction solar cells can be increased by adding an optical spacer. $\mathrm{ZnO}$ was chosen as optical spacer material (and also functions as ETL), because flat layers can be prepared by spincoating from a solution of $\mathrm{ZnO}$ nanoparticles [11,24], making an annealing step unnecessary. In Fig. 3 a we show that the calculated AM1.5 absorption in a PF10TBT:PCBM blend layer (on glass, $150 \mathrm{~nm}$ ITO and $80 \mathrm{~nm}$ PEDOT:PSS, with a LiF/Al top electrode) can increase or decrease when a thin $\mathrm{ZnO}$ layer is put on top of the blend layer, depending on the thickness of both the $\mathrm{ZnO}$ and the blend layer. For a 150 and $180 \mathrm{~nm}$ thick blend layer, the absorption is maximal when the $\mathrm{ZnO}$ spacer layer is $30 \mathrm{~nm}$ thick. For these two thicknesses, the absorption is also calculated as a function of the PEDOT layer thickness, both with and without a $30 \mathrm{~nm} \mathrm{ZnO} \mathrm{layer,} \mathrm{as} \mathrm{shown} \mathrm{in} \mathrm{Fig.} \mathrm{3b.} \mathrm{The}$ measured AM1.5 current density in a $180 \mathrm{~nm}$ PF10TBT device without $\mathrm{ZnO}$ and a $80 \mathrm{~nm}$ PEDOT layer is around $8 \mathrm{~mA} / \mathrm{cm}^{2}$ [8]. The gain in current density by reducing the PEDOT layer and inserting a $30 \mathrm{~nm} \mathrm{ZnO}$ layer is calculated from the absorption in Fig. $3 \mathrm{~b}$ to be about $1 \mathrm{~mA} / \mathrm{cm}^{2}$ (IQE $=75 \%$ and $60 \%$ for $150 \mathrm{~nm}$ and $180 \mathrm{~nm}$ blend thickness respectively), an increase of just over $10 \%$.

\subsection{Tandem structure}

The tandem structure is shown in Fig. 1, where the ETL on the first subcell is $\mathrm{ZnO}(30 \mathrm{~nm})$. Since $\mathrm{ZnO}$ can also act as an optical spacer, we will also consider the influence of this layer on top of the second subcell. The HTL on the ITO/glass is PEDOT:PSS. Both PEDOT:PSS and CuSCN are identified as candidates for the HTL below the second subcell. PEDOT:PSS is an acidic solution and will damage $\mathrm{ZnO}$. CuSCN dissolved in dipropyl sulfide has been used as hole transporting material in dye solar cells [25] and might be more suitable. To study the influence of both polymer blend layer thicknesses, the thickness of the PEDOT:PSS, $\mathrm{ZnO}$ and $\mathrm{CuSCN}$ layer have all been fixed, as indicated in Fig. 1. The blend layer thicknesses modeled range from $50-275 \mathrm{~nm}$. The Al top electrode optically acts as a mirror, resulting in interference effects in the blend layers. Therefore, the absorption in both layers is influenced by a change in either of the thicknesses.

The maximum current in the tandem cell is determined by the polymer blend layer with the lowest current density. The maximum current density in the tandem cell has been calculated using the IQE values of $0.75,0.6$ and 0.5 for film thicknesses $\leq 150 \mathrm{~nm}, 150-275 \mathrm{~nm}$ and $275-375 \mathrm{~nm}$ respectively. The

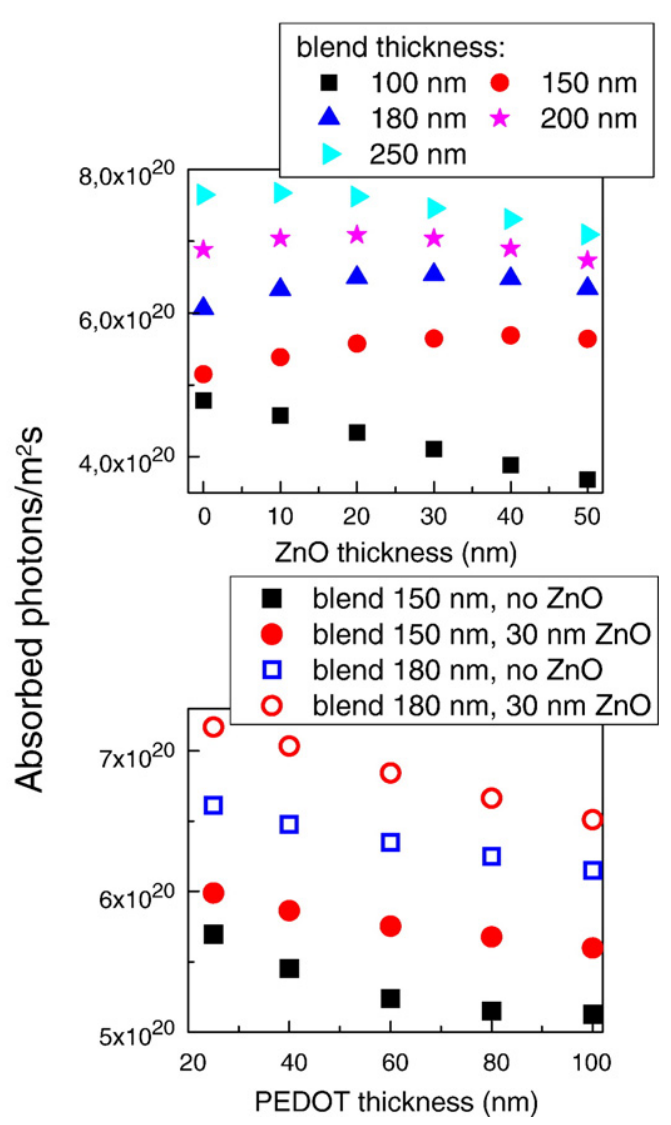

Fig. 3. Optical absorption in a PF10TBT:PCBM blend layer as a function of the thickness of the $\mathrm{ZnO}$ layer on top of the blend layer, for blend thicknesses between 100-250 nm. For a 150 and $180 \mathrm{~nm}$ thick blend layer, the absorption is maximized when the $\mathrm{ZnO}$ layer is $30 \mathrm{~nm}$. In b) the absorption as a function of the PEDOT layer thickness is calculated for these two blend thicknesses, with and without a $30 \mathrm{~nm} \mathrm{ZnO}$ layer. 


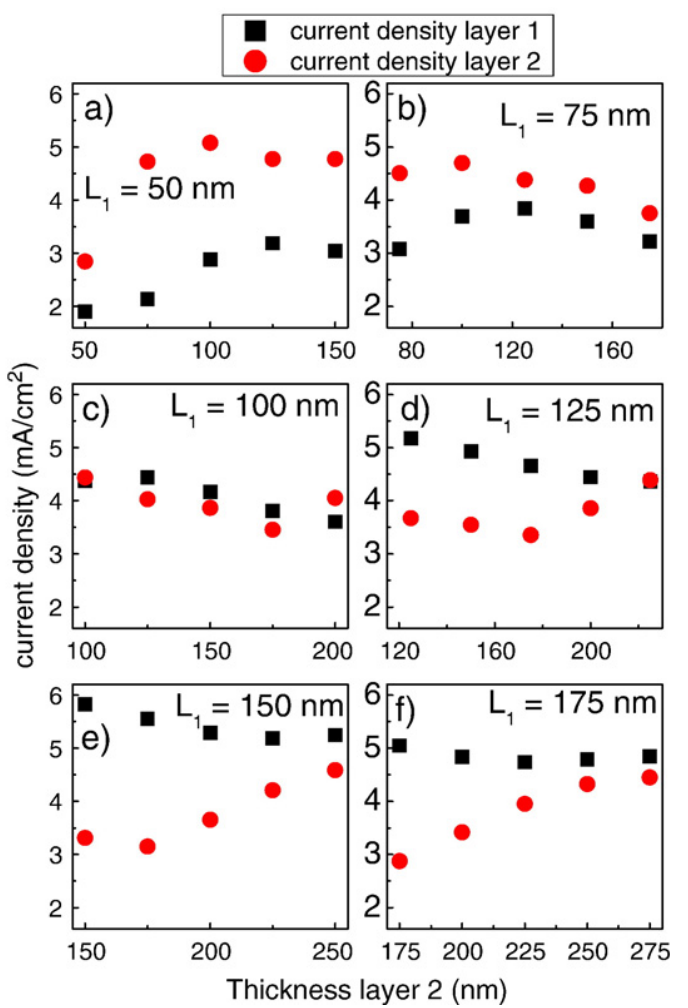

Fig. 4. Calculated current densities in both layer 1 (black squares) and layer 2 (red circles) in a tandem structure. The thickness of layer 1 is a) $50 \mathrm{~nm}, \mathrm{~b}$ ) $75 \mathrm{~nm}$, c) $100 \mathrm{~nm}$, d) $125 \mathrm{~nm}$, e) $150 \mathrm{~nm}$ and f) $175 \mathrm{~nm}$. The thickness of layer 2 is in each figure plotted on the $x$-axis. When $L_{1}$ is only 50 or $75 \mathrm{~nm}$ thick, it is always current limiting. When $L_{1}$ is $150 \mathrm{~nm}$ or above, $L_{2}$ becomes current limiting. The largest limiting current density of $4.6 \mathrm{~mA} / \mathrm{cm}^{2}$ obtained for $L_{1}=150$, $L_{2}=250 \mathrm{~nm}$.

limiting current density is shown in Fig. 4. Due to interference effects, the optical absorption in layer 1 is lower than in layer 2 when the thickness of layer 1 is only 50 or $75 \mathrm{~nm}$, thus layer 1 is then current limiting. When $L_{1}$ is $100 \mathrm{~nm}, L_{2}$ has to be $200 \mathrm{~nm}$ thick in order to be current limiting. When $L_{1}$ is $150 \mathrm{~nm}$ or thicker, $L_{2}$ is always current limiting.

As mentioned before, the current density in the tandem cell is determined by the lowest current of the two subcells. In Fig. 4, it can be seen that this condition results in the largest current density of $4.6 \mathrm{~mA} / \mathrm{cm}^{2}$ for $L_{1}$ with a thickness of $150 \mathrm{~nm}$ and for $L_{2}$ of $250 \mathrm{~nm}$. This current is much lower than the maximum current for a single solar cell of this material, which has a maximum AM1.5 current density around $8 \mathrm{~mA} / \mathrm{cm}^{2}$ for a film about $180 \mathrm{~nm}$ thick [8]. The maximum $V_{\mathrm{oc}}$ that can be expected for the tandem cell is $2 \mathrm{~V}$, assuming each subcell produces a $V_{\text {oc }}$ of $1 \mathrm{~V}$ like in the single solar cell. So assuming no other losses, the efficiency of this tandem structure can be $15 \%$ more than for a single cell. Fig. 4 also shows the importance of the right thickness combinations, as the values for the limiting current density differ by more than a factor of 2. Optical modeling is thus a very helpful tool in choosing appropriate device configurations.

The conversion of light into excitons and ultimately electrons and holes takes place in the polymer:PCBM blend layer. The amount of light that is absorbed in the blend layers also depends on the thickness of the other layers in the tandem


Fig. 5. Current density in $L_{1}(150 \mathrm{~nm}$, black squares $)$ and $L_{2}(250 \mathrm{~nm}$, red circles) as a function of the thickness of a) PEDOT layer thickness, b) $\mathrm{CuSCN}$ layer thickness and c) $\mathrm{ZnO}$ layer thickness determined assuming $\mathrm{IQE}=0.75$ for $L_{1}$ and 0.6 for $L_{2}$.

structure, such as CuSCN, PEDOT and $\mathrm{ZnO}$. For the tandem structure with $L_{1}=150 \mathrm{~nm}$, and $L_{2}=250 \mathrm{~nm}$, we calculated the absorption in both blend layers for a $\mathrm{CuSCN}$ and $\mathrm{ZnO}$ layer thickness of 10, 30, 50 and $70 \mathrm{~nm}$, and for a PEDOT layer thickness of 40, 60, 80 and $100 \mathrm{~nm}$, as shown in Fig. 5. When the thickness of one of these layers is varied, all other layer thicknesses are kept constant at the same values as in Fig. 1. The absorption and current density in $L_{1}$ and $L_{2}$ depend on the $\mathrm{CuSCN}$ and $\mathrm{ZnO}$ layer thickness. From Fig. 5 it can be seen that the largest current density in $L_{2}$ is obtained for a $\mathrm{ZnO}$ and CuSCN layer of $10 \mathrm{~nm}$ thickness, and a PEDOT layer of $40 \mathrm{~nm}$

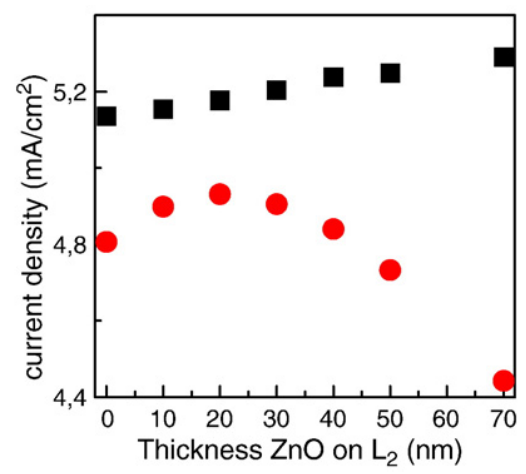

Fig. 6. Influence of a $\mathrm{ZnO}$ spacer layer on top of the second subcell on the current density in layer $1(150 \mathrm{~nm})$ and in layer $2(250 \mathrm{~nm})$. 
thickness. The optical absorption is maximum for zero thickness of the PEDOT layer, but a finite PEDOT layer is necessary for electronic and processing reasons. If we take all these values into the tandem structure, the maximum current density is $4.8 \mathrm{~mA} / \mathrm{cm}^{2}$, resulting in a maximum efficiency increase of $20 \%$ compared to a single cell device.

The optical absorption and current density in $L_{2}$ could further be enhanced by putting a $\mathrm{ZnO}$ layer on top of $L_{2}$. This is calculated for the same tandem structure, with $L_{1}=150 \mathrm{~nm}$, and $L_{2}=250 \mathrm{~nm}, \mathrm{ZnO}$ and CuSCN are both $10 \mathrm{~nm}$ and PEDOT is $40 \mathrm{~nm}$ like above, and shown in Fig. 6. The absorption in $L_{2}$ is only increased for $\mathrm{ZnO}$ layer thicknesses of 10 and $20 \mathrm{~nm}$. The corresponding current density, assuming $\mathrm{IQE}=0.6$, is $4.9 \mathrm{~mA} / \mathrm{cm}^{2}$.

With a maximum limiting current density of $4.9 \mathrm{~mA} / \mathrm{cm}^{2}$ the overall performance of the tandem cell could ideally be $23 \%$ larger than for the measured single cell device [8]. This is assuming that each subcell produces the same voltage as a single cell device, and there are no further losses in fill factor. However, it was shown that along with the reduction in IQE with film thickness, the fill factor reduces as well [10]. Besides electron and hole transport, the function of the $\mathrm{ZnO}$ and $\mathrm{CuSCN}$ layers is also to protect the bottom polymer blend layer from being damaged, so it is necessary that these layers are closed and flat. It is not known if very thin films of only $10 \mathrm{~nm}$ will be closed, and thus experimentally this thickness might be too thin. Taking all these factors into account, it is not likely that the total efficiency of an optimized tandem cell, with identical materials in the two subcells, will exceed the efficiency of an optimized single junction solar cell, despite the fact that in a single cell with maximum current density not all light is absorbed. Therefore we conclude that, apart from the increased complexity of processing tandem structures, it will be more fruitful to optimize a single cell device by reducing the PEDOT:PSS layer thickness and by inserting a thin $\mathrm{ZnO}$ layer. For improved tandem performance, two materials with different bandgaps are needed, such as PF10TBT and the recently published low band gap material PCPDTBT [26,5]. Also, when materials with different bandgaps are employed, the right thickness combination will be important for obtaining optimal current densities, and the modeling process described here will be necessary.

\section{Conclusions}

We have shown that optical modeling is a useful tool to find improvements in light absorption in solar cells. The optical absorption in solar cells consisting of a single junction of PF10TBT:PCBM can be enhanced by $10 \%$ by inserting a thin
(30 $\mathrm{nm})$ electron transport layer $(\mathrm{ZnO})$ which also acts as an optical spacer and by reducing the thickness of the hole transport layer (PEDOT). The current density in a tandem structure consisting of two PF10TBT:PCBM blend layers is strongly dependent on the thicknesses of both blend layers, and achieves a maximum for a combination of blend layers with thicknesses of $150 \mathrm{~nm}$ and $250 \mathrm{~nm}$. This thickness combination, combined with a thin HTL and two ETL layers could lead to an increase in current density around $20 \%$, although the overall efficiency of a tandem will also depend on interface quality, the values of $V_{\mathrm{oc}}$ and the fill factor. Experiments are currently in progress to verify the optical modeling results.

\section{Acknowledgement}

This work was funded by SenterNovem via the EOS Long Term program ZOMER (EOS LT 03026). This work forms part of the research program of the Dutch Polymer Institute (DPI), project \# 524.

\section{References}

[1] S.E. Shaheen, D.S. Ginley, G.E. Jabbour, MRS Bull. 30 (2005) 10.

[2] V. Shrotriya, et al., Adv. Funct. Mat. 16 (2006) 2016.

[3] S.E. Shaheen, et al., Appl. Phys. Lett 78 (2001) 841.

[4] M.A. Green, et al., Prog. Photovolt.: Res. Appl. 14 (2006) 455.

[5] J. Peet, et al., Nat. Mater. 6 (2007) 497.

[6] C. Waldauf, et al., Appl. Phys. Lett. 89 (2006) 33517.

[7] W. Ma, et al., Adv. Funct. Mater. 15 (2005) 1617.

[8] L.H. Slooff, et al., Appl. Phys. Lett. 90 (2007) 143506.

[9] A. Gadisa, et al., Thin Solid Films 515 (2007) 3126.

[10] D.J.D. Moet, et al., Mat. Res. Soc. Symp. Proc. 974 (2007) 0974-CC03-09.

[11] J. Gilot, et al., Appl. Phys. Lett. 90 (2007) 143512.

[12] A. Hadipour, et al., Adv. Funct. Mater. 16 (2006) 1897.

[13] K. Kawano, N. Ito, T. Nishimori, J. Sakai, Appl. Phys. Lett. 88 (2006) 073514.

[14] V. Shrotriya, E.H-E. Wu, G. Li, Y. Yao, Y. Yang, Appl. Phys. Lett. 88 (2006) 06104.

[15] J. Burdick, T. Glatfelter, Sol. Cells 18 (1986) 301.

[16] K. Büchner, A. Schönecker, proceedings 10th ECPVSEC, 1991, p. 107.

[17] J.Y. Kim, et al., Science 317 (2007) 222.

[18] W.Theiss Hard- and Software, Dr.-Bernhard-Klein-Str. 110, D-52078 Aachen, Germany; www.mtheiss.com.

[19] L.A.A. Petterson, L.S. Roman, O. Inganäs, J. Appl. Phys. 86 (1999) 487.

[20] N.K. Persson, H. Arwin, O. Inganäs, J. Appl. Phys. 97 (2005) 034503.

[21] N.K. Persson, O. Inganäs, Sol. Energy Mater. Sol. Cells 90 (2006) 3491.

[22] V.D. Mihailetchi, L.J.A. Koster, J.C. Hummelen, P.W.M. Blom, Phys. Rev. Lett. 93 (2004) 216601.

[23] S. Lacic, O. Iganäs, J. Appl. Phys. 97 (2005) 124901.

[24] W.J.E Beek, thesis University of Eindhoven, The Netherlands (2005).

[25] B.C. O’Regan, F. Lenzmann, J. Phys. Chem., B 108 (2004) 4342.

[26] D. Mühlbacher, et al., Adv. Mat. 18 (2006) 2884. 